\title{
Chronic Neurodegeneration After Traumatic Brain Injury: Alzheimer Disease, Chronic Traumatic Encephalopathy, or Persistent Neuroinflammation?
}

\author{
Alan I. Faden • David J. Loane
}

Published online: 25 November 2014

(C) The American Society for Experimental NeuroTherapeutics, Inc. 2014

\begin{abstract}
It has long been suggested that prior traumatic brain injury (TBI) increases the subsequent incidence of chronic neurodegenerative disorders, including Alzheimer disease, Parkinson disease, and amyotrophic lateral sclerosis. Among these, the association with Alzheimer disease has the strongest support. There is also a long-recognized association between repeated concussive insults and progressive cognitive decline or other neuropsychiatric abnormalities. The latter was first described in boxers as dementia pugilistica, and has received widespread recent attention in contact sports such as professional American football. The term chronic traumatic encephalopathy was coined to attempt to define a "specific" entity marked by neurobehavioral changes and the extensive deposition of phosphorylated tau protein. Nearly lost in the discussions of post-traumatic neurodegeneration after traumatic brain injury has been the role of sustained neuroinflammation, even though this association has been well established pathologically since the 1950 s, and is strongly supported by subsequent preclinical and clinical studies. Manifested by extensive microglial and astroglial activation, such chronic traumatic brain inflammation may be the most important cause of post-traumatic neurodegeneration in terms of prevalence. Critically, emerging preclinical studies indicate that persistent neuroinflammation and associated neurodegeneration may be treatable long after the initiating insult(s).
\end{abstract}

Keywords Traumatic brain injury $\cdot$ Neurodegeneration . Concussion · Repetitive mild TBI · Alzheimer disease . Chronic traumatic encephalopathy $\cdot$ Microglial activation . Chronic traumatic brain inflammation

A. I. Faden $(\varangle) \cdot$ D. J. Loane

Department of Anesthesiology and Shock, Trauma and

Anesthesiology Research (STAR) Center, University of Maryland

School of Medicine, Health Sciences Facility II (HSFII), \#S247 20,

Penn Street, Baltimore, MD 21201, USA

e-mail: afaden@anes.umm.edu

\section{Introduction}

It has been recognized that traumatic brain injury (TBI) may be associated with the subsequent development of chronic neurodegenerative disorders. A prior history of TBI has been reported to increase the incidence of Alzheimer disease (AD) and other dementias [1-7], including younger onset dementias [8]. Since the 1920s, repeated mild TBI (mTBI) in boxers has been linked to later onset neuropsychiatric symptoms and signs. Similar symptoms and brain pathology have been reported following multiple mTBI in other contact sports, particularly American football, and termed chronic traumatic encephalopathy (CTE) [9-12]. Delayed chronic neuropsychiatric alterations following repeated concussions have also been increasingly recognized in military personnel exposed to improvised explosive devices [13-15].

TBI is the most heterogeneous of neurological disorders, with a complex and multifactorial pathobiology [16]. The etiology of $\mathrm{AD}$ has been strongly linked to $\beta$-amyloid $(\mathrm{A} \beta)$ and amyloid plaques. The fact that TBI can cause rapid elevations of brain amyloid and early deposition of amyloid plaques, even in younger individuals, has provided a suggested pathobiological linkage between TBI and AD [17]. Yet certain pathological features differ, and some recent controlled epidemiologic studies have suggested that TBI is better associated with delayed-onset dementias other than $\mathrm{AD}[6,7,18]$.

The deposition of hyperphosphorylated tau protein has been proposed as both a mechanism and pathognomonic feature of CTE [10, 12]. Although hyperphosphorylated tau deposition and neurofibrillary tangles (NFTs) have been reported in the vast majority of cases of patients with a sportsrelated diagnosis of CTE, some of even the best studied boxer cases did not show this feature [19], and many recent reports used such deposits to define the condition. In addition, many cases of CTE show diffuse brain atrophy and other 
pathological features included amyloid plaques, which raise questions about tau as the likely major causative mechanism.

Animal studies show that TBI, including repeated mTBI, can cause persistent neurodegeneration and related cognitive or other behavioral changes [20-25]. Such delayed chronic neurodegeneration has also increasingly been reported in clinical neuroimaging studies [26-32]. Both experimental and clinical reports have suggested strong associations between post-traumatic neurodegeneration and persistent neuroinflammation $[20,22,23,33-38]$, raising the possibility that chronic neurotoxic inflammation may be a major contributor to progressive cell loss and dementia. Microglial activation has been proposed as an important pathobiologic mechanism in major neurodegenerative disorders, including $\mathrm{AD}[39,40]$. Microglial activation has also been reported in the pathology of documented CTE cases [41], although, unfortunately, it does not appear to have been specifically examined in most cases. Underscoring the potential importance of neuroinflammation as a causative factor in post-traumatic degeneration and associated neuropsychiatric symptoms are recent publications showing that highly delayed, targeted anti-inflammatory treatments in experimental TBI models can improve behavioral and pathological outcomes [42-44].

\section{TBI and AD}

\section{Epidemiologic Studies}

Although a history of TBI has widely been accepted as a major risk factor for $\mathrm{AD}$, this association has not been clearly established. Many older studies have reported a significant association between TBI and AD [1-4]. In 1991, Mortimer et al. [3] performed a meta-analysis of case-control studies examining the relationship between $\mathrm{AD}$ and TBI, using predefined inclusion criteria. A more recent meta-analysis conducted by Fleminger et al. [45] sought to replicate the findings of Mortimer et al. [3]; they included both the 8 prior studies and 7 subsequent reports that met specified criteria. Both meta-analyses revealed a significant association in men, but not in women. However, analysis of the 7 most recent studies alone failed to find a significant association in either men or women [45].

Over the last several years a number of epidemiologic studies have examined the relationship between TBI and AD or dementias. A very large recent nationwide cohort study from Sweden by Nordstrom et al. [8] evaluated over 800,000 men conscripted for military service over a mean period of 33 years; more than 45,000 had at least 1 TBI. After adjusting for covariates, there was no significant association for $\mathrm{AD}$ in individuals with single mTBI, $2 \mathrm{mTBI}$, or a single severe TBI. However, there was a significant association with other dementias [8]. Three other large recent studies showed significant associations between TBI and dementias, but not specifically $\operatorname{AD}[6,7,46]$. One was a nationwide cohort study by Lee et al. [7] of $>700,000$ individuals from Taiwan, with $>28,000$ cases of mTBI. This study concluded that mTBI was a significant risk factor for subsequent development of dementia [7]. In a retrospective cohort study, Wang et al. [6] reported on over 225,000 patients, and Barnes et al. [46] examined 188,000 older veterans followed for an average of 9 years. After correcting for confounds, these latter 2 studies reported a $60 \%$ increased risk of dementia. Finally, a recent smaller study by Dams-O'Connor et al. [47] followed 4200 dementia-free individuals aged 65 years or older that were evaluated biannually with a mean follow-up of 7.4 years; a history of TBI with loss of consciousness did not increase the risk for subsequent development of $\mathrm{AD}$ or dementia. Taken together, the literature supports the conclusion that TBI is a significant risk factor for subsequent development of dementia, but the association with $\mathrm{AD}$ seems tenuous at best.

\section{Mechanistic Associations}

Deposition of $A \beta$ in brain and increased axonal $A \beta$ have been consistently reported even in the early period after TBI, with persistent increases years following repeated $\mathrm{mTBI}$ or a single severe insult [48-52]. In fact, a recent study using the carbon 11-labeled Pittsburgh Compound B positron emission tomography ligand demonstrated deposition of $\mathrm{A} \beta$ in cortical gray matter and striatum in patients with head injury followed for 1 year after TBI [53]. The predominant amyloid identified has been $A \beta_{1-42}[54,55]$, the most toxic form of this peptide [56-58]. Others have demonstrated elevated expression of the amyloid precursor protein in cortex from hours to years after TBI [59-62]. Moreover, presenilin-1 and $\beta$-amyloid converting enzyme are found in swollen axons characteristic of diffuse axonal injury after TBI, along with amyloid precursor protein, in both the pig diffuse TBI model and in humans [59, 62-64]. Thus, all the critical factors for generating $A \beta$ are present concurrently after TBI, and it has been proposed that subsequent axonal degeneration allows tissue deposition of this peptide $[65,66]$. As it has been shown that $A \beta$ can migrate trans-synaptically [67], it is possible that $A \beta$ generation in primary injury areas can reach more distant sites to promulgate the process. $A \beta$ plaques have been reported in approximately $30 \%$ of patients who die early after TBI [51], and occur across the age spectrum [52]. Another study demonstrated the presence of NFTs that contain hyperphosphorylated tau, as well as $\mathrm{A} \beta$, in as many as onethird of patients surviving more than 1 year after head injury [49].

It should be noted that the amyloid plaques reported after TBI are typically diffuse and not the neuritic form more typically found in later stage AD [68]. Given the weak epidemiological association between $\mathrm{AD}$ and TBI, it is questionable 
whether these $\mathrm{A} \beta$ plaques progress to $\mathrm{AD}$. However, increased $A \beta_{1-42}$ is highly neurotoxic, likely contributing to both post-traumatic apoptosis and inflammation [69-71]. Thus, $\mathrm{A} \beta$ release and deposition may contribute to the progressive neurodegenerative changes observed after TBI, as well as to the increased risk for dementias. Furthermore, Loane et al. [72] have demonstrated that $\beta$-amyloid converting enzyme knockout mice show improved outcomes following moderate-to-severe TBI compared with wild-type controls, and that inhibition of $\gamma$-secretase activity is neuroprotective in the same model. Thus, distinct from contributing to $\mathrm{AD}$, post-traumatic release of $\mathrm{A} \beta$ may contribute to secondary neurodegeneration and cognitive dysfunction.

\section{CTE}

The neurobehavioral profile following repeated TBI, which has been termed CTE, was first formally described in boxers in 1928 by Martland [73], and further detailed in a larger randomized sample of boxers in 1969 by Roberts [74]. The latter reported a $17 \%$ incidence of a relatively stereotypic behavioral pattern that included neuropsychiatric, cognitive, and motor changes. In 1973, Corsellis et al. [75] described in detail the key neuropathological features of CTE in a group boxers exposed to repetitive brain trauma. Recently, Smith et al. [19] critically reviewed the chronic neuropathological changes that have been reported after TBI, including repetitive insults. Among the 140 cases of CTE summarized, 66 involved athletes with repeated TBI and 23 were military personnel. Although neuropsychiatric symptoms were not always detailed, many of the clinical features of the nonboxers paralleled the earlier descriptions of dementia pugilistica, including emotional lability, depression, suicidal ideation, and aggressive behavior; but cognitive and motor changes appeared to be less frequently noted.

Tau pathology has been proposed as a pathognomonic feature of CTE $[10,12]$. Although 133 of the total cases demonstrated presence of NFTs [19], many cases defined CTE on the basis of such pathology. Given this definitional issue, as well as selection bias and the absence of larger controlled studies, it is questionable whether CTE reflects a true tauopathy - as opposed to more complex pathobiology that includes hyperphosphorylated tau (NFTs) as one important component, among others [19]. For example, even in the best defined CTE samples of former boxers, $>10 \%$ of reported pathological cases did not include tau pathology. That CTE may reflect more multifactorial pathology is indicated by the high incidence of amyloid plaques and TAR DNA-binding protein 43 in CTE. In addition, other frequent pathological changes include the presence of multifocal neuronal loss and diffuse brain atrophy, as well as pathological changes in the cerebellum, striatum, and white matter. Thus, CTE should be characterized as a disorder with "polypathology" [19].

Although neuroinflammation has also been reported in some cases [41], most pathology reports have not directly evaluated such changes. Moreover, NFTs are observed chronically in up to $30 \%$ of the neuropathology cases following a single moderate-to-severe TBI [49]. In addition, Hawkins et al. [76] have reported the rapid accumulation of tau oligomers after TBI in rats. Thus, distinctions involving tau pathology, single versus multiple TBI, and CTE may not be so clear. It has been suggested that the localization of hyperphosphorylated tau, particularly in the depths of sulci, may help to define this condition $[10,12]$. However, as indicated, even in well-defined boxer cases, tau changes may not be found [19].

Although CTE has received enormous attention as an important consequence of sports-related repeated head injury, the frequency of CTE as a consequence of repeated mTBI is unknown. But given the very high incidence of repeated concussive and subconcussive insults in contact supports like American football, the likely incidence of CTE in this population must be rather low. Importantly, although the focus on CTE has helped to underscore the potential consequences of repeated brain trauma in high-contact sports, it also appears to have deflected focus from post-traumatic changes that are far more frequent yet highly consequential, such as progressive neurodegeneration and neuroinflammation.

\section{Progressive Neurodegeneration After TBI}

There is strong experimental and clinical evidence that a single TBI can cause progressive neurodegeneration over months to years following the insult [21, 22, 25-27, 30, 32]. Using a fluid percussion model in rats, Smith et al. [25] showed progressive atrophy and neuronal cell death over 1 year; regions demonstrating greatest loss included cortex, hippocampus, thalamus, and septum. More recently, Loane et al. [22] used longitudinal $7 \mathrm{~T}$ magnetic resonance imaging and stereological histological assessment to demonstrate progressive lesion expansion and hippocampal loss over 1 year following controlled cortical impact (CCI) injury in mice. Many clinical imaging studies have reported longitudinal changes after TBI consistent with progressive neurodegeneration over periods ranging from 6 months to 4 years [26-32]. Most used repeated diffusion tensor imaging. Changes were found in both gray matter and white matter tracts, and in some reports changes were correlated with neuropsychological alterations. Although most of the reports examined patients with severe TBI, similar findings of progressive neurodegeneration have been demonstrated after moderate and even single mild head injuries [28, 32, 77]. A recent review by Keightley et al. [78] critically evaluated 16 reports in children following TBI, 
which demonstrated progressive degeneration in the hippocampus, thalamus, striatum, brain stem, and white mattersimilar to changes reported in adults.

Outside of the CTE-related literature, whether chronic neurodegeneration occurs in participants of high-impact sports and the potential relationship with mild TBI have not been well studied. Very recently, Singh et al. [79] used magnetic resonance imaging to evaluate hippocampal volume changes and relation to concussion history in American collegiate football athletes. They reported significantly smaller hippocampal volumes in football players compared with healthy age-matched controls, with smaller volumes among players with a concussion history compared to those without. A significant inverse relationship was found between hippocampal volumes, as well as reaction times, and years playing football. Although considered preliminary, this study may suggest that a longer history of even subconcussion exposures may contribute to subsequent brain atrophy.

\section{Chronic Neuroinflammation After TBI}

TBI has long been known to cause acute classical and neurogenic inflammation that is associated with cytokine release $[80,81]$. Indeed, many neuroprotective strategies have been directed at such inflammation or related factors [81-84]. Also well established, but less well appreciated is that clinical TBI can cause persistent microglial activation [34, 37, 38, 85-87], and that such chronic inflammation may contribute to neurodegeneration. Recently, Johnson et al. [34] demonstrated that reactive microglia were present in $28 \%$ of brains examined more than 1 year after a single TBI, along with evidence of white matter degeneration in such cases. As only the corpus callosum and parasaggital cortex were examined, and not deeper structures such as thalamus that show both degeneration and chronic microglial activation [37], the likely incidence of chronic neuroinflammation after TBI is likely much higher than reported in this study. Ramlackhansingh et al. [37] used the positron emission tomography ligand [11C](R)PK11195 to evaluate chronic neuroinflammatory changes in patients with head injury followed for many months to years after the initial trauma. They demonstrated increased microglial activation up to 17 years after a single TBI; such inflammation was not located at the lesion site but rather bilaterally at more distant sites such as thalamus and putamen [37]. Moreover, the locus of thalamic inflammation correlated with cognitive changes, suggesting that the inflammatory process may be mechanistically involved with chronic behavioral changes. In addition, recent studies have demonstrated chronically elevated proinflammatory cytokine levels in the serum or cerebrospinal fluid of patients with head injury after TBI, which predict unfavorable outcomes, including neurobehavioral changes such as post-traumatic stress disorder or suicidal ideation [88-90].

Experimental studies strongly support these clinical observations and suggest both mechanisms involved and potential therapeutic strategies [20, 22, 23, 33, 35, 36, 91]. Loane et al. [22] recently showed that TBI in mice caused persistent microglial activation, which was associated with progressive lesion expansion and hippocampal neurodegeneration, up to 1 year post-trauma [22]. Chronically activated microglia expressed major histocompatibility complex class II (CR3/ 43), CD68, and nicotinamide adenine dinucleotide phosphate oxidase (NOX2) at the lesion margins at 1 year, along with evidence of oxidative stress. Multiple experimental studies have demonstrated that repeated mTBI can also cause persistent microglial activation associated with pathology [20, 23, 92]. Shitaka et al. [92] used a repeated closed head injury model in mice to show that reactive microglia were localized in areas adjacent to injured axons at 7 weeks postinjury. Mouzon et al. [23] reported that repeated mTBI in mice caused persistent neuroinflammation and continuing white matter degradation, associated with long-term cognitive deficits up to 18 months post-trauma. In addition, Aungst et al. [20] used a lateral fluid percussion model in rats to demonstrate that repeated mTBI, but not single mTBI, caused persistent chronic microglial activation associated with chronic neurodegeneration, behavioral deficits, and electrophysiological changes; repeated mTBI recapitulated changes caused by single moderate injury with regard to microglial activation, neurodegeneration, and associated neurological dysfunction.

To further address whether persistent microglial activation after TBI contributes to chronic neurodegeneration and behavioral deficits, several studies have examined the therapeutic impact of modulating such inflammation long after the injury. Byrnes et al. [42] treated mice 1 month after CCI with a single intracerebroventricular injection of the metabotropic glutamate receptor 5 agonist (R,S)-2-chloro-5hydroxyphenylglycine, which acts as an NOX2 inhibitor to attenuate microglial activation [93-95]. Such treatment markedly reduced inflammation, lesion volume, and neuronal loss at 4 months postinjury, with ex vivo diffusion tensor imaging showing marked preservation of white matter tracks in treated animals versus vehicle-treated TBI controls [42]. Protective effects were blocked by concurrent systemic treatment with an allosteric metabotropic glutamate receptor 5 antagonist. Piao et al. [43] showed that delayed voluntary exercise beginning 5 weeks after mouse CCI reduces chronic microglial activation, progressive neurodegeneration, and behavioral deficits; the protective mechanism appeared to be through inhibition of NOX2, similar to what was suggested in the (R,S)-2-chloro-5hydroxyphenylglycine study by Byrnes et al. [42]. In addition, Rodgers et al. [44] recently demonstrated that delayed treatment with the anti-inflammatory drug Ibudilast - a phosphodiesterase inhibitor - at 1 month after lateral fluid percussion 
in rats reduced chronic anxiety behavior and reactive gliosis in the thalamus at 6 months postinjury.

Although most of the studies detailed above underscore the neurotoxic effects of persistent microglial activation after TBI, post-traumatic neuroinflammation is highly complex, including multiple microglial phenotypes (M1 vs M2a,b,c), as well as effects of systemic inflammatory cells such as macrophages and other white blood cells [83]. Given that M2 phenotypes have anti-inflammatory and neurorestorative effects [96], why has most emphasis been placed on the neurotoxic M1 phenotype? It has been proposed that NOX2 activation acts as a switch between M1 and M2 activation states [97], serving to activate the former and suppress the latter. Given that experimental evidence indicates that NOX2 is chronically activated after TBI [22], this would favor the persistent expression of

\section{Chronic neurodegeneration after TBI}

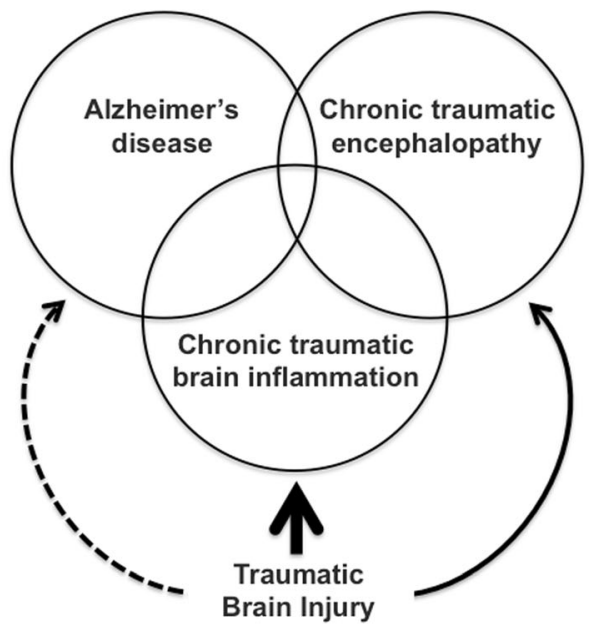

\begin{tabular}{|l|l|l|}
\hline \multicolumn{1}{|c|}{ Alzheimer's disease } & \multicolumn{1}{|c|}{$\begin{array}{c}\text { Chronic traumatic } \\
\text { brain inflammation }\end{array}$} & \multicolumn{1}{|c|}{$\begin{array}{c}\text { Chronic traumatic } \\
\text { encephalopathy }\end{array}$} \\
\hline Biochemical mechanisms & Microglial activation & Phosphorylated tau \\
\hline A (APP, PS-1, BACE) & Oxidative stress (NOX2) & A $\beta$ \\
Phosphorylated tau & & TDP-43 \\
TDP-43 & \multicolumn{2}{|l}{ Microglial activation } \\
\hline Pathology & Inflammation & NFTs \\
\hline A $\beta$ plaques & Atrophy and cell loss & Atrophy and cell loss \\
Atrophy and cell loss & & A $\beta$ plaques \\
NFTs & & Inflammation \\
Inflammation & & \multicolumn{2}{|l}{}
\end{tabular}

Fig. 1 Chronic neurodegeneration after traumatic brain injury (TBI) - a complex and multifactorial pathobiology. Single or repeated TBI initiates complex biochemical mechanisms that lead to chronic neurodegeneration and delayed chronic neuropsychiatric changes. The biochemical and pathological features of Alzheimer's disease, chronic traumatic brain inflammation, and chronic traumatic encephalopathy following TBI are shown. $\mathrm{A} \beta=\beta$-amyloid; $\mathrm{APP}=$ amyloid precursor protein; PS- $1=$ presenilin-1; BACE $=\beta$-amyloid converting enzyme; TDP-43 $=$ TAR DNA-binding protein 43 ; NFTs $=$ neurofibrillary tangles; NOX2 $=$ NADPH oxidase the M1 and highly neurotoxic phenotype. One consequence of continued M1 expression may be to create an environment that is unfavorable to the survival of new neurons generated in response to trauma [43]. However, it should be recognized that phagocytic microglia may help clear $\mathrm{A} \beta$ plaques after injury [98].

There is no established nomenclature for persistent posttraumatic neuroinflammation. To distinguish this condition from acute inflammatory mediated degeneration, several terms may be considered. The persistent neuroinflammation and associated neurodegeneration are features found in chronic noninfectious encephalitis, such as autoimmune encephalitis or paraneoplastic limbic encephalitis [99, 100]. Although chronic traumatic encephalitis may therefore be appropriately descriptive for this condition, its eponym would cause confusion with that well established for CTE. Less confusing terms would be chronic traumatic neuroinflammation, or chronic traumatic brain inflammation (CTBI). We favor the latter, which reflects the brain localization and has the eponym CTBI. Importantly, recent studies indicate that CTBI may be treatable late after injury, with reduced chronic neurodegeneration and improved neurological outcomes [42-44], offering potential opportunity for effective late therapeutic intervention in human head injury.

\section{Conclusions}

TBI is a highly heterogeneous disorder, which initiates complex biochemical and structural alterations that may continue for months or years. Although the association between TBI and classical chronic neurodegenerative disorders has some epidemiological support, more recent large cohort studies have raised questions about the relationship of TBI to even $\mathrm{AD}$ - the best supported of these associations. Instead, the collected evidence indicates that head injury causes chronic neurodegeneration and dementias that are likely multifactorial, consistent with the complex and diverse pathological changes that are observed (Fig. 1). Although CTE and AD have received the major attention as chronic brain disorders following TBI, CTBI appears to be considerably more frequent as a contributing mechanism of late brain atrophy and cognitive decline. More than an issue of nomenclature, recognition of the important pathogenic role of persistent inflammation after TBI may lead to new therapies that attenuate progressive tissue loss after head injury.

Acknowledgments This work was supported by National Institutes of Health grants R01NS037313 and R01NS052568 (A.I. Faden), and R01NS082308 (D.J. Loane).

Required Author Forms Disclosure forms provided by the authors are available with the online version of this article. 


\section{References}

1. Graves AB, White E, Koepsell TD, et al. The association between head trauma and Alzheimer's disease. Am J Epidemiol 1990;131: 491-501.

2. Mortimer JA, French LR, Hutton JT, Schuman LM. Head injury as a risk factor for Alzheimer's disease. Neurology 1985;35:264-267.

3. Mortimer JA, van Duijn CM, Chandra V, et al. Head trauma as a risk factor for Alzheimer's disease: a collaborative re-analysis of casecontrol studies. EURODEM Risk Factors Research Group. Int J Epidemiol 1991;20(Suppl. 2):S28-S35.

4. Plassman BL, Havlik RJ, Steffens DC, et al. Documented head injury in early adulthood and risk of Alzheimer's disease and other dementias. Neurology 2000;55:1158-1166.

5. Salib E, Hillier V. Head injury and the risk of Alzheimer's disease: a case control study. Int J Geriatr Psychiatry 1997;12:363-368.

6. Wang HK, Lin SH, Sung PS, et al. Population based study on patients with traumatic brain injury suggests increased risk of dementia. J Neurol Neurosurg Psychiatry 2012;83:1080-1085.

7. Lee YK, Hou SW, Lee CC, Hsu CY, Huang YS, Su YC. Increased risk of dementia in patients with mild traumatic brain injury: a nationwide cohort study. PLoS One 2013;8:e62422.

8. Nordstrom P, Michaelsson K, Gustafson Y, Nordstrom A. Traumatic brain injury and young onset dementia: a nationwide cohort study. Ann Neurol 2014;75:374-381.

9. Omalu BI, DeKosky ST, Minster RL, Kamboh MI, Hamilton RL, Wecht $\mathrm{CH}$. Chronic traumatic encephalopathy in a National Football League player. Neurosurgery 2005;57:128-234.

10. McKee AC, Cantu RC, Nowinski CJ, et al. Chronic traumatic encephalopathy in athletes: progressive tauopathy after repetitive head injury. J Neuropathol Exp Neurol 2009;68:709-735.

11. Omalu B, Bailes J, Hamilton RL, et al. Emerging histomorphologic phenotypes of chronic traumatic encephalopathy in American athletes. Neurosurgery 2011;69:173-183.

12. McKee AC, Stern RA, Nowinski CJ, et al. The spectrum of disease in chronic traumatic encephalopathy. Brain 2013;136:43-64

13. Tate CM, Wang KK, Eonta S, et al. Serum brain biomarker level, neurocognitive performance, and self-reported symptom changes in soldiers repeatedly exposed to low-level blast: a breacher pilot study. J Neurotrauma 2013;30:1620-1630.

14. MacDonald CL, Johnson AM, Wierzechowski L, et al. Prospectively assessed clinical outcomes in concussive blast vs nonblast traumatic brain injury among evacuated US military personnel. JAMA Neurol 2014;71:994-1002.

15. MacDonald CL, Johnson AM, Nelson EC, et al. Functional status after blast-plus-impact complex concussive traumatic brain injury in evacuated United States military personnel. J Neurotrauma 2014;31:889-898.

16. Loane DJ, Faden AI. Neuroprotection for traumatic brain injury: translational challenges and emerging therapeutic strategies. Trends Pharmacol Sci 2010;31:596-604.

17. Johnson VE, Stewart W, Smith DH. Traumatic brain injury and amyloid-beta pathology: a link to Alzheimer's disease? Nat Rev 2010;11:361-370.

18. Fratiglioni L, Ahlbom A, Viitanen M, Winblad B. Risk factors for late-onset Alzheimer's disease: a population-based, case-control study. Ann Neurol 1993;33:258-266.

19. Smith DH, Johnson VE, Stewart W. Chronic neuropathologies of single and repetitive TBI: substrates of dementia? Nat Rev Neurol 2013;9:211-221

20. Aungst SL, Kabadi SV, Thompson SM, Stoica BA, Faden AI. Repeated mild traumatic brain injury causes chronic neuroinflammation, changes in hippocampal synaptic plasticity, and associated cognitive deficits. J Cereb Blood Flow Metab 2014;34: 1223-1232.
21. Dixon CE, Kochanek PM, Yan HQ, et al. One-year study of spatial memory performance, brain morphology, and cholinergic markers after moderate controlled cortical impact in rats. J Neurotrauma 1999;16:109-122.

22. Loane DJ, Kumar A, Stoica BA, Cabatbat R, Faden AI. Progressive neurodegeneration after experimental brain trauma: association with chronic microglial activation. J Neuropathol Exp Neurol 2014;73: 14-29.

23. Mouzon BC, Bachmeier C, Ferro A, et al. Chronic neuropathological and neurobehavioral changes in a repetitive mild traumatic brain injury model. Ann Neurol 2014;75:241-254

24. Pierce JE, Smith DH, Trojanowski JQ, McIntosh TK. Enduring cognitive, neurobehavioral and histopathological changes persist for up to one year following severe experimental brain injury in rats. Neuroscience 1998;87:359-369.

25. Smith DH, Chen XH, Pierce JE, et al. Progressive atrophy and neuron death for one year following brain trauma in the rat. $\mathrm{J}$ Neurotrauma 1997;14:715-727.

26. Bendlin BB, Ries ML, Lazar M, et al. Longitudinal changes in patients with traumatic brain injury assessed with diffusion-tensor and volumetric imaging. Neuroimage 2008;42:503-514.

27. Farbota KD, Sodhi A, Bendlin BB, et al. Longitudinal volumetric changes following traumatic brain injury: a tensor-based morphometry study. J Int Neuropsychol Soc 2012;18:1006-1018.

28. Kumar R, Husain M, Gupta RK, et al. Serial changes in the white matter diffusion tensor imaging metrics in moderate traumatic brain injury and correlation with neuro-cognitive function. J Neurotrauma 2009;26:481-495.

29. Ng K, Mikulis DJ, Glazer J, et al. Magnetic resonance imaging evidence of progression of subacute brain atrophy in moderate to severe traumatic brain injury. Arch Phys Med Rehabil 2008;89(12 Suppl.):S35-S44.

30. Sidaros A, Engberg AW, Sidaros K, et al. Diffusion tensor imaging during recovery from severe traumatic brain injury and relation to clinical outcome: a longitudinal study. Brain 2008;131:559-572.

31. Sidaros A, Skimminge A, Liptrot MG, et al. Long-term global and regional brain volume changes following severe traumatic brain injury: a longitudinal study with clinical correlates. Neuroimage 2009;44:1-8.

32. Trivedi MA, Ward MA, Hess TM, et al. Longitudinal changes in global brain volume between 79 and 409 days after traumatic brain injury: relationship with duration of coma. J Neurotrauma 2007;24: 766-771.

33. Acosta SA, Tajiri N, Shinozuka K, et al. Long-term upregulation of inflammation and suppression of cell proliferation in the brain of adult rats exposed to traumatic brain injury using the controlled cortical impact model. PLoS One 2013;8:e53376.

34. Johnson VE, Stewart JE, Begbie FD, Trojanowski JQ, Smith DH, Stewart W. Inflammation and white matter degeneration persist for years after a single traumatic brain injury. Brain 2013;136:28-42.

35. Nagamoto-Combs K, McNeal DW, Morecraft RJ, Combs CK. Prolonged microgliosis in the rhesus monkey central nervous system after traumatic brain injury. J Neurotrauma 2007;24:1719-1742.

36. Nonaka M, Chen XH, Pierce JE, et al. Prolonged activation of NFkappaB following traumatic brain injury in rats. J Neurotrauma 1999;16:1023-1034.

37. Ramlackhansingh AF, Brooks DJ, Greenwood RJ, et al. Inflammation after trauma: microglial activation and traumatic brain injury. Ann Neurol 2011;70:374-283.

38. Smith C, Gentleman SM, Leclercq PD, et al. The neuroinflammatory response in humans after traumatic brain injury. Neuropathol Appl Neurobiol 2013;39:654-666.

39. Eikelenboom P, van Exel E, Hoozemans JJ, Veerhuis R, Rozemuller AJ, van Gool WA. Neuroinflammation - an early event in both the history and pathogenesis of Alzheimer's disease. Neurodegener Dis 2010;7:38-41. 
40. Perry VH, Nicoll JA, Holmes C. Microglia in neurodegenerative disease. Nat Rev Neurol 2010;6:193-201.

41. Saing T, Dick M, Nelson PT, Kim RC, Cribbs DH, Head E. Frontal cortex neuropathology in dementia pugilistica. J Neurotrauma 2012;29:1054-1070.

42. Byrnes KR, Loane DJ, Stoica BA, Zhang J, Faden AI. Delayed mGluR5 activation limits neuroinflammation and neurodegeneration after traumatic brain injury. J Neuroinflammation 2012;9:43.

43. Piao CS, Stoica BA, Wu J, et al. Late exercise reduces neuroinflammation and cognitive dysfunction after traumatic brain injury. Neurobiol Dis 2013;54:252-263.

44. Rodgers KM, Deming YK, Bercum FM, et al. Reversal of established traumatic brain injury-induced, anxiety-like behavior in rats after delayed, post-injury neuroimmune suppression. J Neurotrauma 2014;31:487-497.

45. Fleminger S, Oliver DL, Lovestone S, Rabe-Hesketh S, Giora A. Head injury as a risk factor for Alzheimer's disease: the evidence 10 years on; a partial replication. J Neurol Neurosurg Psychiatry 2003;74:857-862.

46. Barnes DE, Kaup A, Kirby KA, Byers AL, Diaz-Arrastia R, Yaffe $\mathrm{K}$. Traumatic brain injury and risk of dementia in older veterans. Neurology 2014;83:312-319.

47. Dams-O'Connor K, Gibbons LE, Bowen JD, McCurry SM, Larson $\mathrm{EB}$, Crane PK. Risk for late-life re-injury, dementia and death among individuals with traumatic brain injury: a population-based study. J Neurol Neurosurg Psychiatry 2013;84:177-182.

48. Ikonomovic MD, Uryu K, Abrahamson EE, et al. Alzheimer's pathology in human temporal cortex surgically excised after severe brain injury. Exp Neurol 2004;190:192-203.

49. Johnson VE, Stewart W, Smith DH. Widespread tau and amyloidBeta pathology many years after a single traumatic brain injury in humans. Brain Pathol 2012;22:142-149.

50. Roberts GW, Allsop D, Bruton C. The occult aftermath of boxing. J Neurol Neurosurg Psychiatry 1990;53:373-378.

51. Roberts GW, Gentleman SM, Lynch A, Graham DI. beta A4 amyloid protein deposition in brain after head trauma. Lancet 1991;338: 1422-1423.

52. Roberts GW, Gentleman SM, Lynch A, Murray L, Landon M, Graham DI. Beta amyloid protein deposition in the brain after severe head injury: implications for the pathogenesis of Alzheimer's disease. J Neurol Neurosurg Psychiatry 1994;57:419-425.

53. Hong YT, Veenith T, Dewar D, et al. Amyloid imaging with carbon 11-labeled Pittsburgh compound B for traumatic brain injury. JAMA Neurol 2014;71:23-31.

54. DeKosky ST, Abrahamson EE, Ciallella JR, et al. Association of increased cortical soluble abeta 42 levels with diffuse plaques after severe brain injury in humans. Arch Neurol 2007;64:541-544.

55. Gentleman SM, Greenberg BD, Savage MJ, et al. A beta 42 is the predominant form of amyloid beta-protein in the brains of shortterm survivors of head injury. Neuroreport 1997;8:1519-1522.

56. Lesne S, Koh MT, Kotilinek L, et al. A specific amyloid-beta protein assembly in the brain impairs memory. Nature 2006;440: 352-357.

57. Shankar GM, Li S, Mehta TH, et al. Amyloid-beta protein dimers isolated directly from Alzheimer's brains impair synaptic plasticity and memory. Nat Med 2008;14:837-842.

58. Walsh DM, Klyubin I, Fadeeva JV, et al. Naturally secreted oligomers of amyloid beta protein potently inhibit hippocampal longterm potentiation in vivo. Nature 2002;416:535-539.

59. Smith DH, Chen XH, Iwata A, Graham DI. Amyloid beta accumulation in axons after traumatic brain injury in humans. J Neurosurg 2003;98:1072-1077.

60. Sherriff FE, Bridges LR, Sivaloganathan S. Early detection of axonal injury after human head trauma using immunocytochemistry for beta-amyloid precursor protein. Acta Neuropathol 1994;87:5562.
61. Gentleman SM, Nash MJ, Sweeting CJ, Graham DI, Roberts GW. Beta-amyloid precursor protein (beta APP) as a marker for axonal injury after head injury. Neurosci Lett 1993;160:139-144.

62. Chen XH, Johnson VE, Uryu K, Trojanowski JQ, Smith DH. A lack of amyloid beta plaques despite persistent accumulation of amyloid beta in axons of long-term survivors of traumatic brain injury. Brain Pathol 2009; 19:214-223.

63. Uryu K, Chen XH, Martinez D, et al. Multiple proteins implicated in neurodegenerative diseases accumulate in axons after brain trauma in humans. Exp Neurol 2007;208:185-192.

64. Smith DH, Chen XH, Nonaka M, et al. Accumulation of amyloid beta and tau and the formation of neurofilament inclusions following diffuse brain injury in the pig. J Neuropathol Exp Neurol 1999;58:982-992.

65. Iwata A, Chen XH, McIntosh TK, Browne KD, Smith DH. Longterm accumulation of amyloid-beta in axons following brain trauma without persistent upregulation of amyloid precursor protein genes. J Neuropathol Exp Neurol 2002;61:1056-1068.

66. Chen XH, Siman R, Iwata A, Meaney DF, Trojanowski JQ, Smith DH. Long-term accumulation of amyloid-beta, beta-secretase, presenilin-1, and caspase-3 in damaged axons following brain trauma. Am J Pathol 2004;165:357-371.

67. Nath S, Agholme L, Kurudenkandy FR, Granseth B, Marcusson J, Hallbeck M. Spreading of neurodegenerative pathology via neuronto-neuron transmission of beta-amyloid. J Neurosci 2012;32:87678777.

68. Horsburgh K, Cole GM, Yang F, et al. beta-amyloid (Abeta)42(43), abeta42, abeta40 and apoE immunostaining of plaques in fatal head injury. Neuropathol Appl Neurobiol 2000;26:124-132.

69. Yankner BA, Dawes LR, Fisher S, Villa-Komaroff L, Oster-Granite ML, Neve RL. Neurotoxicity of a fragment of the amyloid precursor associated with Alzheimer's disease. Science 1989;245:417-420.

70. Mattson MP, Cheng B, Davis D, Bryant K, Lieberburg I, Rydel RE. beta-Amyloid peptides destabilize calcium homeostasis and render human cortical neurons vulnerable to excitotoxicity. J Neurosci 1992;12:376-389.

71. Matsuoka Y, Picciano M, Malester B, et al. Inflammatory responses to amyloidosis in a transgenic mouse model of Alzheimer's disease. Am J Pathol 2001;158:1345-1354.

72. Loane DJ, Pocivavsek A, Moussa CE, et al. Amyloid precursor protein secretases as therapeutic targets for traumatic brain injury. Nat Med 2009; 15:377-379.

73. Martland J. Punch drunk. JAMA 1928;91:1103-1107.

74. Roberts G. Brain damage in boxers: a study of the prevalence of traumatic encephalopathy amoung ex-professional boxers. Pitman, London, 1969.

75. Corsellis JA, Bruton CJ, Freeman-Browne D. The aftermath of boxing. Psychol Med 1973;3:270-303.

76. Hawkins BE, Krishnamurthy S, Castillo-Carranza DL, et al. Rapid accumulation of endogenous tau oligomers in a rat model of traumatic brain injury: possible link between traumatic brain injury and sporadic tauopathies. J Biol Chem 2013;288:17042-17050.

77. Zhou Y, Kierans A, Kenul D, et al. Mild traumatic brain injury: longitudinal regional brain volume changes. Radiology 2013;267: 880-890.

78. Keightley ML, Sinopoli KJ, Davis KD, et al. Is there evidence for neurodegenerative change following traumatic brain injury in children and youth? A scoping review. Front Hum Neurosci 2014;8:139.

79. Singh R, Meier TB, Kuplicki R, et al. Relationship of collegiate football experience and concussion with hippocampal volume and cognitive outcomes. JAMA 2014;311:1883-1888.

80. Woodcock T, Morganti-Kossmann MC. The role of markers of inflammation in traumatic brain injury. Front Neurol 2013;4:18.

81. Ziebell JM, Morganti-Kossmann MC. Involvement of pro- and antiinflammatory cytokines and chemokines in the pathophysiology of traumatic brain injury. Neurotherapeutics 2010;7:22-30. 
82. Donkin JJ, Vink R. Mechanisms of cerebral edema in traumatic brain injury: therapeutic developments. Curr Opin Neurol 2010;23: 293-299.

83. Kumar A, Loane DJ. Neuroinflammation after traumatic brain injury: opportunities for therapeutic intervention. Brain Behav Immun 2012;26:1191-1201.

84. Lewis KM, Turner RJ, Vink R. Blocking neurogenic inflammation for the treatment of acute disorders of the central nervous system. Int J Inflamm 2013;2013:578480.

85. Gentleman SM, Leclercq PD, Moyes L, et al. Long-term intracerebral inflammatory response after traumatic brain injury. Forensic Sci Int 2004;146:97-104.

86. Faden AI. Microglial activation and traumatic brain injury. Ann Neurol 2011;70:345-346.

87. Engel S, Schluesener H, Mittelbronn M, et al. Dynamics of microglial activation after human traumatic brain injury are revealed by delayed expression of macrophage-related proteins MRP8 and MRP14. Acta Neuropathol 2000;100:313-322.

88. Lindqvist D, Wolkowitz OM, Mellon S, et al. Proinflammatory milieu in combat-related PTSD is independent of depression and early life stress. Brain Behav Immun 2014.

89. Kumar RG, Boles JA, Wagner AK. Chronic inflammation after severe traumatic brain injury: characterization and associations with outcome at 6 and 12 months postinjury. J Head Trauma Rehabil 2014 Jun 4.

90. Juengst SB, Kumar RG, Arenth PM, Wagner AK. Exploratory associations with Tumor Necrosis Factor-alpha, disinhibition and suicidal endorsement after traumatic brain injury. Brain Behav Immun 2014;41:134-143.
91. Holmin S, Mathiesen T. Long-term intracerebral inflammatory response after experimental focal brain injury in rat. Neuroreport 1999;10:1889-1891.

92. Shitaka Y, Tran HT, Bennett RE, et al. Repetitive closed-skull traumatic brain injury in mice causes persistent multifocal axonal injury and microglial reactivity. J Neuropathol Exp Neurol 2011;70: 551-567.

93. Byrnes KR, Stoica B, Loane DJ, Riccio A, Davis MI, Faden AI. Metabotropic glutamate receptor 5 activation inhibits microglial associated inflammation and neurotoxicity. Glia 2009;57:550-560.

94. Loane DJ, Stoica BA, Byrnes KR, Jeong W, Faden AI. Activation of mGluR5 and inhibition of NADPH oxidase improves functional recovery after traumatic brain injury. J Neurotrauma 2013;30:403-412.

95. Loane DJ, Stoica BA, Pajoohesh-Ganji A, Byrnes KR, Faden AI. Activation of metabotropic glutamate receptor 5 modulates microglial reactivity and neurotoxicity by inhibiting NADPH oxidase. J Biol Chem 2009;284:15629-15639.

96. Colton CA. Heterogeneity of microglial activation in the innate immune response in the brain. J Neuroimmune Pharmacol 2009;4:399-418.

97. Choi SH, Aid S, Kim HW, Jackson SH, Bosetti F. Inhibition of NADPH oxidase promotes alternative and anti-inflammatory microglial activation during neuroinflammation. J Neurochem 2012;120:292-301.

98. Mannix RC, Whalen MJ. Traumatic brain injury, microglia, and beta amyloid. Int J Alzheimers Dis 2012;2012:608732.

99. Leypoldt F, Armangue T, Dalmau J. Autoimmune encephalopathies. Ann N Y Acad Sci 2014 Oct 14.

100. Leypoldt F, Wandinger KP. Paraneoplastic neurological syndromes. Clin Exp Immunol 2014;175:336-348. 